\title{
Low cycle fatigue life prediction in shot-peened components of different geometries - Part I: Residual stress relaxation
}

C. You ${ }^{a, *}$, M. Achintha ${ }^{a}$, K.A. Soady ${ }^{b}$, N. Smyth ${ }^{c}$, M.E. Fitzpatrick ${ }^{c}$, P.A.S Reed ${ }^{\text {a }}$

${ }^{a}$ Engineering Materials, Engineering and the Environment, University of Southampton, Highfield, Southampton SO17 1BJ, UK

${ }^{\mathrm{b}}$ Uniper Technologies Ltd., Nottingham NG11 0EE, UK

${ }^{c}$ Faculty of Engineering and Computing, Coventry University, Coventry CV1 5FB , UK

\begin{abstract}
In this study, the residual stress relaxation behaviour occurring during low-cycle fatigue in shot-peened specimens with either a flat or a notched geometry has been studied. A representative low-pressure steam turbine material, FV448, was used. The residual stress and strain hardening profiles caused by shot peening were measured experimentally and were then incorporated into a finite element model. By allowing for both effects of shot peening, the residual stress relaxation behaviour was successfully simulated using this model and correlated well with the experimental data. Although more modelling work may be required to simulate the interaction between shot peening effects and external loads in a range of notched geometries, the model predictions are consistent with the specimens tested in the current study. The novelty of this study lies in the development of such a modelling approach which can be used to effectively simulate the complex interaction between shot peening effects and external loads in notched regions. Compared with the un-notched geometry, the notched geometry was found to be more effective in retaining the improvement in fatigue life resulting from shot peening, by restricting the compressive residual stress relaxation during fatigue loading.
\end{abstract}

Keywords: Shot peening, Eigenstrain, Residual stress relaxation, Finite element modelling

\section{Nomenclature}

$$
\begin{aligned}
\boldsymbol{a}, \boldsymbol{a}_{\boldsymbol{k}} & =\text { backstress tensor } \\
b, Q_{\infty} & =\text { parameters of the isotropic hardening component }
\end{aligned}
$$

\footnotetext{
* Corresponding author. Tel.: +44 (0) 2380599450

Email address: c.you@ soton.ac.uk (C. You)
} 


$$
\begin{aligned}
& C_{i}=\text { coefficients of Chebyshev polynomials } \\
& E=\text { Young's modulus } \\
& f(\boldsymbol{\sigma}-\boldsymbol{a})=\text { equivalent Mises stress } \\
& K_{t}=\text { stress concentration factor } \\
& N=\text { number of Chebyshev polynomials } \\
& R_{a}=\text { arithmetic average roughness } \\
& T_{i}=\text { Chebyshev polynomials } \\
& \text { EBSD = electron backscatter diffraction } \\
& \mathrm{FE}=\text { finite element } \\
& \mathrm{HCF}=\text { high-cycle fatigue } \\
& \mathrm{LCF}=\text { low-cycle fatigue } \\
& \mathrm{XRD}=\mathrm{X} \text {-ray diffraction } \\
& \gamma_{k}, C_{k}=\text { parameters of the kinematic hardening component } \\
& \Delta \varepsilon_{x x}=\text { longitudinal strain range } \\
& \dot{\boldsymbol{\varepsilon}}^{p l}=\text { plastic strain rate component } \\
& \bar{\varepsilon}^{p l}=\text { equivalent plastic strain } \\
& \dot{\varepsilon}^{\dot{p} l}=\text { equivalent plastic strain rate } \\
& \varepsilon_{x x}=\text { longitudinal strain component } \\
& \varepsilon_{x x}^{\text {eigen }}, \varepsilon_{y y}^{\text {eigen }} \text { and } \varepsilon_{z z}^{\text {eigen }}=\text { eigenstrain components for flat geometries } \\
& \varepsilon_{\theta}^{\text {eigen }}, \varepsilon_{y y}^{\text {eigen }} \text { and } \varepsilon_{r}^{\text {eigen }}=\text { eigenstrain components for flat geometries } \\
& v=\text { Poisson's ratio } \\
& \sigma_{0.2}=0.2 \% \text { proof stress } \\
& \sigma^{0}=\text { size of the yield surface } \\
& \sigma_{\text {nom }}=\text { nominal stress } \\
& \sigma_{x x}=\text { longitudinal stress component } \\
& \sigma_{x x_{i}}^{F E}=\text { Individual residual stress modelling results using Chebyshev } \\
& \text { polynomials } \\
& \sigma_{y y}=\text { transverse stress component }
\end{aligned}
$$

\section{Introduction}

Shot peening is a surface treatment which is commonly used in a range of engineering applications to increase the fatigue resistance of metallic components containing stress concentration features, such as the fir-tree bladedisc interface in turbines. During the shot peening process, the surface of the workpiece is bombarded by a stream of small spherical shots acting as tiny peening hammers, producing inhomogeneous plastic deformation 
near the surface. This process typically induces increased surface roughness, strain hardening and compressive residual stresses within the surface layer ${ }^{1,2}$.

Many investigations have focused on the effects of shot peening on fatigue behaviour in different systems ${ }^{3-5}$. Based on these previous studies, it can be concluded that surface roughness has a detrimental influence on the fatigue resistance of components ${ }^{3}$ while compressive residual stresses and strain hardening contribute to improvement in fatigue resistance ${ }^{3-5}$. The overall influence of shot peening on fatigue can be attributed to the combined effects of all these factors, but the beneficial effects of compressive residual stresses and strain hardening usually play a dominant role when surface roughness $R_{a}<5 \mu m^{6}$. In order to more accurately predict the fatigue life of shot-peened components, it is important to investigate the interaction between these shot peening induced effects and the service conditions, especially in stress concentration areas where the effects of shot peening are most difficult to predict.

During low-cycle fatigue loading, residual stress relaxation usually occurs, which may reduce the benefits of shot peening in improving fatigue life. Generally, the most significant residual stress relaxation induced by mechanical loading is observed during the first cycle, when the superposition of the applied and residual stresses exceeds the local yield strength, causing plastic deformation ${ }^{7,8}$. This is regarded as quasi-static relaxation which is affected by the monotonic yield strength of the material. In subsequent cycles, residual stress relaxation depends on the cyclic yield strength and usually exhibits a linear reduction with the logarithm of the number of cycles ${ }^{7,9}$. In order to include the effects of residual stresses into life assessment methods, an efficient way to accurately predict the relaxation behaviour is required.

Finite element (FE) modelling has been shown to be powerful in evaluating the effects of shot peening and laser shock peening on fatigue life ${ }^{8,10-13}$. As a necessary first step, the initial residual stress field before fatigue loading has to be reconstructed in the FE model. To date, one of the most successful modelling methods to achieve this is the eigenstrain approach ${ }^{8,10,12-14}$. The eigenstrain is defined as the "permanent misfit strain acting as the perturbation that causes the material to respond elastically to achieve a stress-equilibrium state within the component, thus generating residual stresses". 
Previous studies ${ }^{11,13}$ have demonstrated that for the same material, as long as the sample is at least four times thicker than the depth of the eigenstrain distribution, the eigenstrain is predominantly a characteristic of the peening process and is largely independent of the sample geometry. Unlike residual stresses, the eigenstrain can therefore be transferred between different geometries which are treated with the same shot peening process. It is noteworthy that relatively simple geometries (such as plates and blocks), where there is no significant change between the samples studied, were used in ${ }^{11,13}$. Coratella et al. ${ }^{15}$ further validated this transferability from a flat, planar surface to curved surfaces. However, in more complex geometries (such as the notched geometry with high stress concentration studied here), this may be less reasonable since the eigenstrain distribution introduced by the peening process is likely to be affected by changes in the component geometry. Dewald and Hill ${ }^{16}$ suggested that this effect should be accounted for in the eigenstrain approach in order to improve the accuracy of residual stress reconstruction. Nevertheless, it is still very difficult to accurately predict the effects of complex geometries on eigenstrain components during the peening process. Therefore, application of the eigenstrain approach to simulate the residual stress field in shot/laser-peened components with complex geometries is still very limited. This has restricted a wider application of the eigenstrain approach in residual stress modelling. Since shot peening is often applied to stress concentration areas (such as fir tree blade connectors) in service, this is a significant drawback that should be addressed.

The authors have previously presented ${ }^{17}$ the logic of an eigenstrains-based finite element modelling of residual stresses and the relaxation of residual stress in a shot-peened flat geometry. The work presented in the paper is limited to a single geometry and a simple material model (i.e. an isotropic hardening model). The current paper extends the previous work and shows the application of the technique to model residual stress distribution and stress relaxation during fatigue of complex notched geometries which are representative of real-life applications. The novelty of the work also includes modelling the complex interaction between the geometry and the applied loads. A combined isotropic/kinematic material model, which is more representative of the material behaviour of the material used in the experiments (FV448), has also been used in the modelling work. A sensitivity analysis has also been carried out in the current paper to study the effect of uncertainty of the input data on model predictions. To the best of the authors' knowledge, accurate simulations of residual stress relaxation occurring during fatigue in shot-peened notched samples have not been reported previously. 
As a starting point, a shot-peened flat geometry was modelled and the modelling results were validated against experimental results. The experimental results of residual stress and strain hardening data were used in the current modelling framework to obtain input data for FE analyses. Once the modelling technique has been validated for the simple flat geometry, the model has then been extended to analyse the notched geometries. It should be noted that no attempt is made in the current paper to compare the flat geometry and notched geometry due to the lack of practical relevance since flat geometries are not commonly peened in practice. The flowchart illustrating the modelling procedure is shown in Fig. 1. In the first step, two 3-D FE models (a flat and a notched model) without shot peening (SP) effects were developed using ABAQUS/Standard (v6.13). An elasto-plastic material model representative of the monotonic mechanical properties of FV448 was also developed and was incorporated into the FE models. These preliminary models were validated by a test measuring the strain evolution in safety-critical regions during fatigue loading using strain gauges. Then, an inverse eigenstrain method ${ }^{12,14}$, which was based on the elastic behaviour of the material, was used to determine the eigenstrain distribution caused by shot peening in flat samples. The determined eigenstrain profile was incorporated into the FE models as the source of residual stresses. The application of this residual stress modelling approach has also been extended to the notched case by considering the effects of the notched geometry on eigenstrain profiles. Furthermore, to account for the shot-peening-induced strain hardening effects, varying mechanical properties have been defined for the material within the surface layer in the FE model. This has been achieved by defining the initial condition (plastic strain caused by shot peening) of the elasto-plastic material model at different depths, based on measurements from an electron back-scatter diffraction (EBSD) based approach. Finally, the residual stress relaxation behaviour occurring during fatigue in both un-notched and notched specimens was investigated using the developed FE model, and also compared with corresponding experimental results measured by XRD.

\section{Experimental program}

\subsection{Material}

The material under investigation is FV448, a 9-12 \% Cr tempered martensitic steel which is representative of the type of material used in low-pressure turbine blades. This barstock material was austenitised at $1150^{\circ} \mathrm{C}$, oil 
quenched, tempered at $650^{\circ} \mathrm{C}$ and then air cooled. The microstructure and composition of this material have been detailed in ${ }^{2}$.

\subsection{Specimen}

\subsubsection{Specimens used for shot peening treatments}

As shown in Fig. 2, two types of specimens with different geometries have been used in this study: a plain bend bar with a flat geometry and a U-notched sample (stress concentration factor, $K_{t}=1.58$ ) representing the fir tree root geometry of a turbine blade. $K_{t}$ was calculated by comparing the stress parallel to the tensile axis, $\sigma_{x x}$ (predicted from an elastic FE analysis using a model without shot peening effects) with the equivalent elastic stress calculated using simple beam theory.

Two shot peening treatments were used in this study. MI230R 13A 200\% (intensity: 13A, coverage: 200\%), labelled as T0, was chosen as the baseline shot peening treatment since it is industrially applied to steam turbine blades. Another process, MI110R 04A 200\% (intensity: 4A, coverage: 200\%), labelled as T1, was considered as a comparison. The T0 process was applied to both the plain and notched samples while the T1 process was only applied to the plain sample owing to time constraints. All the shot peening treatments were carried out by Metal Improvement Company Derby Division.

\subsubsection{Specimens used for validating the preliminary FE model}

As indicated in Fig. 1, the preliminary FE model (before shot peening effects are included) has to be experimentally validated. To achieve this, some ground samples were electropolished instead of being shotpeened to remove the surface layer affected by the grinding process $(\sim 200 \mu \mathrm{m})$. These electropolished samples were used to carry out validation tests measuring the strain evolution in safety-critical regions during fatigue loading, which was then used to validate the counterparts predicted by the preliminary FE model. In order to more conveniently attach the strain gauge to the notch root, a larger notched specimen was used as shown in Fig. 2(c). Dimensions of the plain sample used in this validation test were as shown in Fig. 2(a).

\subsection{Residual stress measurements}


The residual stress distribution caused by shot peening was determined by the $\sin ^{2} \psi$ method using the X-ray diffraction (XRD) technique with a $\mathrm{Cr}-\mathrm{K} \alpha \mathrm{X}$-ray source. The measurements were taken on the $\{211\}$ diffraction peak at a $2 \theta$ angle of $156.4^{\circ}$. A collimator of $1 \mathrm{~mm}$ diameter was used for residual stress measurements taken on the plain sample. In order to minimise the error associated with taking residual stress measurements on a curved surface, a collimator of $0.5 \mathrm{~mm}$ diameter was used for the notched sample. The residual stress data were collected in two orthogonal directions $\left(\sigma_{x x}\right.$ and $\left.\sigma_{y y}\right)$ in the centre of the top surface of the plain sample, and at the notch root of the notched sample. An incremental layer removal method achieved by electropolishing was used to characterise the residual stress profile in the depth $(z)$ direction.

To evaluate the residual stress relaxation behaviour, the residual stress distribution was determined at different total life fractions (after 1 cycle and at estimated 50\% life, at a load ratio $R=0.1$ ) in the T0 shot-peened samples. 3- and 4-point bend tests were carried out on a servo-hydraulic Instron 8502 for the notched and plain specimens with a loading span of $15 \mathrm{~mm}$, as shown in Fig. 2. All the tests were carried out at room temperature since the maximum service temperature in LP turbines is $\sim 250^{\circ} \mathrm{C}$ which is below the creep regime of FV448 and hence behaviour at room temperature was believed to be reasonably representative of service conditions ${ }^{18}$.

\subsection{Strain evolution measurements during fatigue loading}

The aim of this test, using electropolished samples, was to experimentally validate the preliminary FE model without shot peening effects. The longitudinal strain $\left(\varepsilon_{x x}\right)$ evolution in the centre of the plain bend bar top surface and at the notch root of the notched specimen during fatigue loading was measured using strain gauges. A strain gauge with a gauge length of $3.18 \mathrm{~mm}$ and a strain range of $\pm 5 \%$ was selected for the plain sample. For the notched sample, in order to reduce the measurement error caused by the curvature, a strain gauge with a gauge length of $0.38 \mathrm{~mm}$ and a strain range of $\pm 3 \%$ was selected. Both types of strain gauge were supplied by Vishay Precision Group.

\section{Experimental results}

3.1. Residual stress profiles in the as-peened condition 
Fig. 3(a) shows the measured residual stress distributions in the plain specimens. Although the T1 process results in a shallower compressive residual stress layer $(\sim 0.19 \mathrm{~mm})$ than the T0 process $(\sim 0.35 \mathrm{~mm})$ owing to its lower peening intensity, it seems that the maximum stress magnitude is independent of the peening intensity for these conditions. This observation is consistent with the results reported in ${ }^{19}$, which found that simply increasing the peening intensity may not necessarily increase the peak compressive residual stress magnitude if it is already close to the local yield strength. In addition, there is no significant difference between the $\sigma_{x x}$ and $\sigma_{y y}$ profiles in the plain specimen for either peening condition. In contrast, in the T0 shot-peened notched sample, $\sigma_{x x}$ appears to be $\sim 16 \%$ more compressive than $\sigma_{y y}$, as shown in Fig. 3(b). However, the depth of the compressive residual stress layer seems unaffected by the notched geometry, remaining the same as in the T0 plain specimen.

The measurement error was determined by calculating the sample standard deviation over 5 bi-directional measurements (10 data points) at different locations on the uncycled shot-peened plain sample; the $95 \%$ confidence range was $\pm 50 \mathrm{MPa}{ }^{18}$. Owing to time constraints and equipment availability, this was assumed to be the confidence range within which all data could be quoted rather than carrying out extensively repeated measurements for each sample.

\subsection{Residual stress relaxation}

The T0 plain samples were loaded for 1 cycle in this test. The corresponding surface strain ranges $\left(\Delta \varepsilon_{x x}\right)$ were predicted using the developed FE model including shot peening effects and are detailed in Section 4. In order to investigate the link between residual stress relaxation and the retention of the benefits of shot peening, two load levels with $\Delta \varepsilon_{x x}=0.42 \%$ and $0.55 \%$ were chosen based on the corresponding total life reported in ${ }^{20}$. Compared with the un-peened samples, the T0 process showed no clear benefits in improving fatigue life when $\Delta \varepsilon_{x x}=0.55 \%$ but doubled the fatigue life when $\Delta \varepsilon_{x x}=0.42 \%$. The measured residual stresses shown in Fig. 4 indicate that no clear relaxation is observed when $\Delta \varepsilon_{x x}=0.42 \%$ but a $30-40 \%$ stress relief occurs in both directions $\left(\sigma_{x x}\right.$ and $\left.\sigma_{y y}\right)$ when $\Delta \varepsilon_{x x}=0.55 \%$.

The T0 notched samples were loaded with an estimated notch root strain range of $\Delta \varepsilon_{x x}=0.69 \%$. This value was chosen also because the fatigue life of the un-peened notched sample was found to be doubled by the T0 
process at this load level ${ }^{18}$. As shown in Fig. 5, there is no clear relaxation of $\sigma_{x x}$ after neither 1 loading cycle nor after $50 \%$ total life, which is in contrast to the results of the plain specimen. However, there is a $20 \%$ relaxation of $\sigma_{y y}$ during the first cycle but no further relaxation can be seen in subsequent cycles.

\section{Numerical modelling and discussion}

\subsection{Material model}

A combined nonlinear hardening material model proposed by Chaboche ${ }^{21}$ has been chosen in this study to describe the mechanical properties of the FV448 steel. This constitutive model has been widely applied and has been demonstrated to be robust in describing the mechanical properties of the material ${ }^{8,22}$. It consists of two hardening components: isotropic and kinematic. The isotropic component is used to indicate the size of the yield surface $\left(\sigma^{0}\right)$. The kinematic component describes the position of the yield surface in terms of the backstress $(\boldsymbol{a})$, considering the Bauschinger effect.

In this model, the yield surface is defined by Equation 1, where $f(\boldsymbol{\sigma}-\boldsymbol{a})$ is the equivalent Mises stress; $F<0$ indicates the elastic domain and plastic flow takes place if $F \geq 0$. Equation 2 describes the calculation of the equivalent plastic strain rate, $\dot{\varepsilon}^{p l}$, using the plastic strain rate component, $\dot{\varepsilon}^{p l}$. The isotropic and kinematic components are expressed by Equations 3 and 4 respectively:

$F=f(\boldsymbol{\sigma}-\boldsymbol{a})-\sigma^{0}$

$\dot{\bar{\varepsilon}}^{\dot{p} l}=\sqrt{\left(\frac{2}{3}\right) \dot{\boldsymbol{\varepsilon}}^{p l}: \dot{\boldsymbol{\varepsilon}}^{p l}}$

$\sigma^{0}=\left.\sigma\right|_{0}+Q_{\infty}\left(1-e^{-b \bar{\varepsilon}^{p l}}\right)$

$\dot{\boldsymbol{a}}_{\boldsymbol{k}}=\frac{2}{3} C_{k} \dot{\boldsymbol{\varepsilon}}^{p l}-\gamma_{k} \boldsymbol{a}_{\boldsymbol{k}}\left|\dot{\bar{\varepsilon}}^{p l}\right|, \quad \boldsymbol{a}=\sum_{N-1}^{N} \boldsymbol{a}_{\boldsymbol{k}}$

where $Q_{\infty}$ is the maximum change in $\sigma^{0}$ and $b$ defines the rate at which the yield surface changes with the development of $\bar{\varepsilon}^{p l} . N$ is the total number of backstresses. $C_{k}$ is the initial kinematic hardening moduli and $\gamma_{k}$ determines the decreasing rate of the kinematic hardening moduli with increasing $\bar{\varepsilon}^{p l}$. 
In the present study, the calibration of the material model is based on the monotonic stress-strain relationship of FV448. This simplification was applied for two reasons: firstly, residual stress relaxation has been observed to be most significant during quasi-static loading in different systems ${ }^{7,8,18}$, so an accurate simulation of the first cycle is particularly important; secondly, there is no clear logarithmic reduction in stress with increasing fatigue cycles in the investigated notched samples owing to the high constraint exerted by the notched geometry (relevant results are shown and explained in detail in Section 4.2). Hence, a previously determined RambergOsgood model ${ }^{18,23}$ representative of the monotonic stress-strain relation of FV448 was used to identify the material parameters in Equations 3 and 4. In order to achieve a satisfactory modelling outcome, two kinematic components were used and one of which was linear ${ }^{21}$. Relevant calibrated parameters of this combined material model are given in Table 1.

\subsection{FE models}

Taking advantage of the symmetry, a quarter of the specimen was modelled using 20-node reduced integration 3-D brick elements, as shown in Fig. 6 . The mesh near the surface region has been particularly refined (25-50 $\mu \mathrm{m}$ in thickness, element aspect ratio $<5$ ) in order to better reproduce the stress and strain gradients within the shot peening affected layer.

Before shot peening effects were considered, the preliminary FE models without shot peening effects were validated against the experimentally measured strain evolutions in the electropolished plain $\left(\Delta \varepsilon_{x x}=0.65 \%\right)$ and notched samples $\left(\Delta \varepsilon_{x x}=0.69 \%\right)$ during fatigue loading, as described in Section 2.4. Relevant results are illustrated in Fig. 7, where the nominal stress, $\sigma_{\text {nom }}$, was determined using simple beam theory to indicate the load level. According to the experimental results, ratcheting occurred in the plain sample until stabilisation was achieved after $\sim 30$ cycles, as illustrated in Fig. 7(a). In contrast, elastic shakedown was observed in the notched sample as shown in Fig. 7(b), with no clear plastic deformation beyond the first cycle. This, to some degree, explains why residual stress relaxation is confined to the first cycle in the notched sample as shown in Fig. 5: no further plastic deformation implies that the plastic misfit distribution remains unchanged during subsequent cycles. 
In the modelling work, only one cycle was simulated, as cyclic mechanical properties were not considered by the current material model. As can be seen from Fig. 7, a good correlation between the experimental and modelling results is shown when $\varepsilon_{x x}<1.5 \%$ in the plain bar, and when $\varepsilon_{x x}<0.8 \%$ in the notched geometry. Beyond this range strain hardening is slightly overestimated by the model, which may be attributed to the measurement errors in the experiments and/or the limitation of the assumed material model. However, the discrepancy between the FE modelling and experiments at high strains is not critical to the results presented in the current paper since the applied load range in the flat and the notched geometries analysed in the current study are well covered by this experimental validation. Thus, although the ratcheting behaviour was not predicted, this model seems an appropriate starting point to simulate the quasi-static stress-strain evolution within the first cycle, especially for the notched specimen where cyclic effects are not evident.

\subsection{Modelling the initial residual stress field caused by shot peening}

Modelling the initial residual stress field caused by shot peening is an essential prerequisite to analysing residual stress relaxation during fatigue loading. The full residual stress field can be reconstructed by applying a stressequilibrium step in the model containing eigenstrain. The eigenstrain can be conveniently incorporated into the FE model by specifying anisotropic thermal expansion coefficients that vary with position, together with a uniform (unit) temperature rise ${ }^{12}$. Since the eigenstrain profile is usually unknown and difficult to directly predict, the inverse eigenstrain approach developed by Korsunsky et al. ${ }^{24}$ was implemented. It is essentially an approach to back-fit the eigenstrain distribution from the known residual stress (or residual elastic strain) distribution determined by experimental measurements (e.g. XRD). This analysis requires a choice of a suitable parametric expression to describe the eigenstrain distribution. Once an accurate estimate of the eigenstrain profile is established, the complete residual stress field in the whole component can be determined in the usual way. The advantage of this approach is that the elastic response of the workpiece to the eigenstrain will satisfy equilibrium, compatibility and boundary conditions, and the residual stress field produced will be entirely selfconsistent.

In the current study, the objective is to demonstrate how compressive residual stress profiles, either measured or predicted using appropriate empirical or analytical techniques, can be incorporated into FE models and to 
predict the complete initial residual stress distribution and, most significantly, any changes to it under fatigue loading. Hence the complexities associated with dynamic modelling (such as the strain rate dependency of the target material, the material and size of shots, the contact property of the peened surface, etc.) were not considered in this work. It is reasonable to employ a linear elastic model with properties broadly representative of FV448 (Young's modulus $E=201.3 \mathrm{GPa}$; Poisson's ratio $v=0.3$ ) in the inverse eigenstrain analysis. However, it should be noted that the elasto-plastic material introduced in Section 4.1 has to be used in subsequent residual stress relaxation analysis. This inverse eigenstrain approach was first applied to the plain sample and then its application was extended to the notched sample.

\subsubsection{Modelling plain samples}

In simple geometries such as the plain sample, the eigenstrain distribution is usually assumed to be equi-biaxial owing to the non-directional nature of the plastic deformation induced by the shot peening process. This assumption has been adopted in the present work to determine the in-plane principle eigenstrain components; $\varepsilon_{x x}^{e i g e n}=\varepsilon_{y y}^{e i g e n}$. Considering volume conservation in plastic deformation, the third principal component perpendicular to the peened surface has been defined as $\varepsilon_{z z}^{\text {eigen }}=-2 \varepsilon_{x x}^{\text {eigen }}$. In the present study, Chebyshev polynomials have been adopted to describe the eigenstrain profile as introduced in ${ }^{12} \cdot \varepsilon_{x x}^{\text {eigen }}$ is assumed to vary with depth (z) and is expressed as a linear combination of Chebyshev polynomials $T_{i}(z)$ multiplied by unknown coefficients $C_{i}$, as described by Equation 5 , where $N$ is the number of polynomials. The values of $C_{i}$ were determined by minimising the difference between the experimentally measured residual stress data $\sigma_{x x}(z)$ and the weighted sum of individual modelling results $\sigma_{x x_{i}}^{F E}(z)$ obtained as an elastic response to each eigenstrain base function $T_{i}(z)$, as expressed by Equation 6 where $m$ is the number of experimental data points. It has been proved that, providing the selections are physically reasonable, the best-estimated eigenstrain profile is largely independent of $N$ and the assumed depth of the eigenstrain profile ${ }^{12}$.

$$
\begin{aligned}
& \varepsilon_{x x}^{e i g e n}(z)=\sum_{i=0}^{N-1} C_{i} T_{i}(z) \\
& \min (J)=\sum_{j=1}^{m}\left[\sigma_{x x}(z)-\sum_{i=0}^{N-1} C_{i} \sigma_{x x_{i}}^{F E}(z)\right]^{2}
\end{aligned}
$$


Based on previous findings ${ }^{17}, N=8$ has been chosen for the T0 process and the corresponding depth of the eigenstrain distribution has been assumed to be $0.4 \mathrm{~mm}$. Using the same approach, $N=4$ and a eigenstrain depth of $0.2 \mathrm{~mm}$ were determined for the T1 process. Fig. 8 (a) and (c) show the best-estimated depth profile of $\varepsilon_{x x}^{\text {eigen }}$ for the $\mathrm{T} 0$ and $\mathrm{T} 1$ process respectively. Based on the obtained eigenstrain profiles, the modelled residual stresses in the shot-peened plain samples are shown in Fig. 8 (b) and (d) accordingly. Compared with corresponding experimental data, it is evident that both $\sigma_{x x}$ and $\sigma_{y y}$ distributions have been accurately modelled for the two different shot peening conditions.

\subsubsection{Modelling notched samples}

In the modelling work for the notched sample, $\varepsilon_{\theta}^{\text {eigen }}$ (tangential to the notch curvature) and $\varepsilon_{r}^{\text {eigen }}$ (perpendicular to the notch curvature) have been used as new principal eigenstrain components instead of $\varepsilon_{x x}^{\text {eigen }}$ and $\varepsilon_{z z}^{e i g e n}$. Another principal component is still defined as $\varepsilon_{y y}^{e i g e n}$ (in the transverse direction). Considering the residual stress data presented in this paper for notched samples were collected at the notch root, for consistency with the experimental data shown in Fig. 3-5, the residual stress in the longitudinal direction is still presented as $\sigma_{x x}$.

As discussed previously, the eigenstrain distribution may be affected by the geometry of the sample. This effect has to be properly accounted for in order to more accurately model the residual stress field. Anoop et al. ${ }^{25}$ indicated that the same peening condition would induce less surface stretching in convex geometries than in flat geometries. In contrast, more stretching near the peened surface would be expected in concave geometries, leading to a greater misfit layer and thus a greater compressive residual stress, which is consistent with the results obtained in the present work as shown in Fig. 3. Hence, directly using the equi-biaxial eigenstrain distribution $\left(\varepsilon_{\theta}^{e i g e n}=\varepsilon_{y y}^{e i g e n}\right.$ as shown in Fig. 9 (a), $\left.\varepsilon_{r}^{\text {eigen }}=-2 \varepsilon_{y y}^{\text {eigen }}\right)$ determined from the simple geometry may result in an inaccurate reconstruction of the residual stress field in complex geometries even though the same shot peening process was applied. This hypothesis is confirmed by Fig. 9 (b), which shows a 25-30\% underestimation of $\sigma_{x x}$ in the T0 notched sample by directly using the equi-biaxial eigenstrain profiles 
determined from the T0 plain sample. Other examples showing unsatisfactory modelling results using similar assumptions can be found in ${ }^{16,26}$.

In the notched sample, since more stretching is expected to occur along the notch curvature during the shot peening process, the assumption $\varepsilon_{\theta}^{\text {eigen }}=\varepsilon_{y y}^{\text {eigen }}$ seems less reasonable. So a more accurate simulation can be expected if $\varepsilon_{\theta}^{e i g e n}$ and $\varepsilon_{y y}^{e i g e n}$ can be predicted individually rather than simply assuming an equi-biaxial state $\left(\varepsilon_{\theta}^{e i g e n}=\varepsilon_{y y}^{e i g e n}\right)$. However, it is noted that the conventional inverse eigenstrain method is simply a 1-D solution and evaluating two eigenstrain components simultaneously is non-trivial for the least square analysis. In order to solve this problem, $\varepsilon_{y y}^{\text {eigen }}$ in the notched sample has been assumed to be identical to that in the plain sample subjected to the same shot peening process, as shown in Fig. 8. It is anticipated that $\varepsilon_{y y}^{\text {eigen }}$ is much less affected by the curved geometry than $\varepsilon_{\theta}^{\text {eigen }}$. A detailed study of the stress concentration in the $y y$ direction of the notched samples is beyond the scope of the current paper. For simplicity, no stress concentration feature in the transverse direction of the notch is assumed in the current modelling work. Based on this assumption, the problem was degraded to 1-D. Then the inverse eigenstrain approach was implemented again to predict $\varepsilon_{\theta}^{e i g e n}$. $\varepsilon_{r}^{e i g e n}$ can be determined using the relation $\varepsilon_{r}^{e i g e n}=-\left(\varepsilon_{\theta}^{e i g e n}+\varepsilon_{y y}^{e i g e n}\right)$ considering volume conservation in plastic deformation. Although there may be some stress concentration effect in the transverse direction, it is likely that the inverse eigenstrain analysis used in the current modelling work will to some extent counter any effect due to the relatively low stress concentration in the transverse direction. As it can be seen from the results presented in this paper, the model predictions are at least consistent with the experimental results of the test specimens analysed in the current paper.

Fig. 9 (c) shows the predicted biaxial eigenstrain profiles for the T0 notched specimen; $\varepsilon_{\theta}^{\text {eigen }}$ is $\sim 1.58$ times $\varepsilon_{y y}^{\text {eigen }}$, demonstrating more stretching along the notch curvature as expected. The subsequent residual stress modelling results are presented in Fig. 9 (d), which shows a good correlation with experimental data. It is noteworthy that 1.58 is consistent with the $K_{t}$ value of this notched sample, which implies a relation between the eigenstrain components and the notched geometry. However, the consistency between the $K_{t}$ and the strain ratio needs a further validation because it could be regarded as only a coincidence rather than a physical 
correlation. A detailed analysis of the interaction between shot peening and the geometry of a range of practical peening applications is beyond the scope of the current paper since the primary objective of the current paper is to predict the stress relaxation in the notched geometry considered in the study.

4.4. Modelling the strain hardening effects caused by shot peening

Since the surface layer is usually strain hardened by the shot peening process, it is necessary to incorporate its effects into the FE model in addition to the compressive residual stress effects. Neglecting the strain hardening effects will potentially degrade the accuracy of the simulated residual stress relaxation, thus reducing the accuracy of the developed life assessment method.

EBSD local misorientation data were used to evaluate the plastic strain distribution caused by shot peening, as detailed in ${ }^{2}$. This evaluation was based on a linear relation between the true plastic strain and the kernel average misorientation (KAM). This relation was obtained by calibration based on uniaxial tension and compression tests experiencing known strain hardening levels. Fig. 10 shows the predicted true plastic strain profiles caused by the $\mathrm{T} 0$ and $\mathrm{T} 1$ shot peening processes respectively. This plastic strain profile was incorporated into the FE model as an initial condition of the material model before the loading step. Thus the size of the yield surface $\sigma^{0}$ (Equation 3) and backstresses $\boldsymbol{a}_{\boldsymbol{k}}$ (Equation 4) at different depths can be modified according to the incorporated plastic strain profile.

\subsection{Modelling residual stress relaxation due to service loading}

After incorporating the effects of the residual stress and strain hardening induced by shot peening into the FE model, a load step was defined to simulate the experimental fatigue load. Only one load cycle was simulated as cyclic mechanical properties were not considered in the applied material model. As shown in Fig. 11, good correlation between the simulated and the experimental results was obtained for both the T0 plain and notched samples. This validates the modelling techniques applied in the present study.

According to previous work ${ }^{10,27}$, shot-peened components preferentially show more notable residual stress relaxation in the direction parallel to the load (the longitudinal direction) than in the direction perpendicular to the load (the transverse direction) under uniaxial loading or reverse bending tests. In addition, it has also been 
found that if a higher load was applied, more significant relaxation was normally expected since greater local plastic deformation will lead to more reduction in the plastic misfit (i.e. the eigenstrain). In order to investigate the residual stress relaxation behaviour in the current system, the quasi-static relaxation in both flat and notched specimens has also been simulated at different load levels using the FE model.

The simulated results for the T0 plain sample are shown in Fig. 11 (a) and (b). As expected, the compressive residual stress relaxation in both directions becomes more significant with increasing load. Nevertheless, $\sigma_{x x}$ is much less relaxed than $\sigma_{y y}$ and the depth of the compressive residual stress profile is extended, which seems contradictory to the conclusions drawn by other researchers ${ }^{9,27}$. In fact this is not surprising in the 3- or 4-point bend case: the inhomogeneous plastic deformation generated by the bending process itself develops a compressive residual stress layer after unloading as a result of the constraint exerted by the elastically deformed material beneath. This process compensates for any compressive residual stress relief occurring in the loading (longitudinal) direction. This trend has been found to be more significant in the notched sample as shown in Fig. 11 (c) and (d); there is no clear $\sigma_{x x}$ relaxation and the $\sigma_{x x}$ profile even becomes more compressive at the highest load level $\left(\Delta \varepsilon_{x x}=0.81 \%\right)$. This retention of compressive residual stress is thought to be a result of the high constraint exerted by the notched geometry. Hence, it seems that the notched geometry is more beneficial than the un-notched geometry in maintaining the benefits of shot peening during fatigue loading. This has been validated by the fatigue life data (even in the LCF regime) reported in ${ }^{23}$.

\subsection{Sensitivity analysis}

Although the quasi-static residual stress relaxation can be reasonably predicted using the developed FE model, the prediction is highly dependent on the input data (i.e. the initial residual stress and strain hardening profiles) of the model. Errors in these experimentally determined input data are always inevitable, so a sensitivity analysis investigating how the accuracy of the input data affects the prediction was carried out. In this analysis, three varying eigenstrain and initial true plastic strain profiles were defined as shown in Table 2. The profiles with label $b$ are the baseline profiles which have been used in the preceding analysis. The profiles with labels $a$ and $c$ represent the experimental error range reported in 2 . The parametric analysis matrix is shown in Table 3 , which aims to assess the relative importance of scatter in the initial residual stresses and strain hardening values 
for the model. Analogous with the preceding modelling work, the plain and notched models with varying eigenstrain and initial true plastic strain profiles were loaded for 1 cycle. Then the simulated relaxed residual stresses based on these different initial starting points were compared. The results using the plain models are shown in Fig. 12; only the $\sigma_{x x}$ components are plotted for conciseness. The results for the notched models are omitted for brevity since very similar trends with the plain models were obtained.

From Fig. 12 (a) and (c), it can be seen that the variation of the initial residual stress definition results in different stress distributions after 1 loading cycle. The difference caused by differing initial residual stress conditions can be as much as $100 \mathrm{MPa}$ when $\Delta \varepsilon_{x x}=0.42 \%$; however, this difference decreases to $50 \mathrm{MPa}$ when the load level is increased to give $\Delta \varepsilon_{x x}=0.55 \%$. Hence it can be concluded that the predicted residual stress relaxation is sensitive to the accuracy of the initial residual stress profile but this sensitivity tends to be less significant at high load levels when the effects caused by external loads are more dominant.

In contrast, the effect of the scatter in the initial strain hardening profile is much less notable, according to Fig. 12 (b) (d). As discussed in Section 4.1 and 4.4, strain hardening affects local material properties mainly by modifying the yield surface $\left(\sigma^{0}\right)$ and the backstresses $(\boldsymbol{a})$ in terms of the equivalent plastic strain $\left(\bar{\varepsilon}^{p l}\right)$ as described by Equation 3 and 4 . In the current case, in the area near the surface (depth $<0.1 \mathrm{~mm}$ ) where the strain hardening effects are significant $\left(0.02<\bar{\varepsilon}^{p l}<0.25\right)$, a $17 \%$ variation of the baseline strain hardening profile only results in a $<1.5 \%$ and $<6 \%$ difference in local $\sigma^{0}$ and $\boldsymbol{a}$ respectively, which is insufficient to cause a significant change in the model response especially when the external load level is relatively low.

In life assessment methods, consideration of residual stress relaxation is necessary. As a result of this, this sensitivity analysis will be extended to study the effects of the accuracy of the predicted residual stress relaxation on total life predictions in the companion Part II paper ${ }^{28}$. According to the results presented in Fig. 12, most experimental data (especially those near the peened surface) are just within the range defined by this sensitivity analysis, which makes the extended study more meaningful.

\section{Conclusions}


- An eigenstrain-based FE approach has been developed to predict the quasi-static residual stress relaxation in safety-critical shot-peened regions, taking the example of a stress-concentrating notch. The application of the conventional inverse eigenstrain method has been extended to a notched geometry. In this FE approach, the effects of strain hardening have also been accounted for by modifying the yield strength at different depths. In spite of the fact that more modelling work may be required to simulate the interaction between shot peening effects and external loads in a range of notched geometries, the FE approach developed in the current study has been demonstrated to be both accurate and efficient in evaluating the stress/strain status in safety-critical regions during fatigue loading, which will be especially helpful to the fatigue life prediction of shot-peened components.

- Based on the modelling results, the notched geometry has been found to be more effective in the retention of compressive residual stresses than the un-notched geometry during fatigue loading. This explains why a greater benefit of shot peening in improving fatigue life was observed in the notched specimen than in the un-notched specimen.

- The predicted residual stress relaxation using the developed model is more sensitive to the initial residual stress profile than to the initial strain hardening profile. So ensuring a good accuracy of the residual stress measurement in the as-peened condition is necessary. This sensitivity tends to be less significant at high loading levels when the effects of external loads dominate.

\section{Acknowledgements}

Financial support from China Scholarship Council, the Engineering and Physical Sciences Research Council (EP/K503150/1), and Uniper Technologies Ltd. is gratefully acknowledged. Thanks are also extended to Dr Binyan $\mathrm{He}$ for her assistance in gathering residual stress data and helpful discussions. The authors would also like to thank Gary Harrison from the University of Manchester for his assistance with XRD measurements. The support of the University of Southampton for access to its IRIDIS4 High Performance Computing Facility is also gratefully acknowledged. M.E. Fitzpatrick is grateful for funding from the Lloyd's Register Foundation, a charitable foundation helping to protect life and property by supporting engineering-related education, public engagement and the application of research. 
All data supporting this study are openly available from the University of Southampton repository at http://eprints.soton.ac.uk/390756/ (http://dx.doi.org/10.5258/SOTON/390756 will be used instead when this

DOI is registered after the acceptance of this paper).

\section{Reference}

1. Child DJ, West GD, Thomson RC (2011) Assessment of surface hardening effects from shot peening on a Ni-based alloy using electron backscatter diffraction techniques. Acta Mater. 59: 4825-4834.

2. Soady KA, Mellor BG, West GD, Harrison G, Morris A, Reed PAS (2013) Evaluating surface deformation and near surface strain hardening resulting from shot peening a tempered martensitic steel and application to low cycle fatigue. Int. J. Fatigue. 54: 106-117.

3. Wagner L (1999) Mechanical surface treatments on titanium, aluminum and magnesium alloys. Mat. Sci. Eng. A. 263: 210-216.

4. Altenberger I, Scholtes B, Martin U, Oettel H (1999) Cyclic deformation and near surface microstructures of shot peened or deep rolled austenitic stainless steel AISI 304. Mat. Sci. Eng. A. 264: 1-16.

5. He BY, Soady KA, Mellor BG, Harrison G, Reed PAS (2016) Fatigue crack growth behaviour in the LCF regime in a shot peened steam turbine blade material. Int. J. Fatigue. 82: 280-291.

6. Soady KA (2013) Life assessment methodologies incoroporating shot peening process effects: mechanistic consideration of residual stresses and strain hardening Part 1 - effect of shot peening on fatigue resistance. Mater. Sci. Tech-lond. 29: 637-651.

7. Dalaei K, Karlsson B, Svensson LE (2011) Stability of shot peening induced residual stresses and their influence on fatigue lifetime. Mat. Sci. Eng. A. 528: 1008-1015.

8. Song X, Liu WC, Belnoue JP, et al. (2012) An eigenstrain-based finite element model and the evolution of shot peening residual stresses during fatigue of GW103 magnesium alloy. Int. J. Fatigue. 42: 284-295.

9. Holzapfel H, Schulze V, Vohringer O, Macherauch E (1998) Residual stress relaxation in an AISI 4140 steel due to quasistatic and cyclic loading at higher temperatures. Mat. Sci. Eng. A. 248: 9-18.

10. Benedetti M, Fontanari V, Monelli BD (2010) Numerical Simulation of Residual Stress Relaxation in Shot Peened High-Strength Aluminum Alloys Under Reverse Bending Fatigue. Journal of Engineering Materials and Technology. 132: 011012.

11. Achintha M, Nowell D (2011) Eigenstrain modelling of residual stresses generated by laser shock peening. J. Mater. Process. Tech. 211: 1091-1101.

12. Achintha M, Nowell D, Shapiro K, Withers PJ (2013) Eigenstrain modelling of residual stress generated by arrays of laser shock peening shots and determination of the complete stress field using limited strain measurements. Surf. Coat. Tech. 216: 68-77.

13. Korsunsky AM (2006) Residual elastic strain due to laser shock peening: modelling by eigenstrain distribution. The Journal of Strain Analysis for Engineering Design. 41: 195-204.

14. Korsunsky AM (2005) On the modelling of residual stresses due to surface peening using eigenstrain distributions. The Journal of Strain Analysis for Engineering Design. 40: 817-824.

15. Coratella S, Sticchi M, Toparli MB, Fitzpatrick ME, Kashaev N (2015) Application of the eigenstrain approach to predict the residual stress distribution in laser shock peened AA7050-T7451 samples. Surf. Coat. Tech. 273: 39-49.

16. Hill MR, DeWald AT (2009) Eigenstrain-based model for prediction of laser peening residual stresses in arbitrary three-dimensional bodies. Part 2: model verification. The Journal of Strain Analysis for Engineering Design. 44: 13-27.

17. Achintha M, You C, He BY, Soady K, Reed P (2014) Stress Relaxation in Shot-Peened Geometric Features Subjected to Fatigue: Experiments and Modelling. Advanced Materials Research. 996: 729735.

18. Soady KA, Mellor BG, Shackleton J, Morris A, Reed PAS (2011) The effect of shot peening on notched low cycle fatigue. Mat. Sci. Eng. A. 528: 8579-8588. 
19. Zinn W, Scholtes B (2005) Influence of shot velocity and shot size on Almen intensity and residual stress depth distributions. The 9th international conference on shot peening ICSP9, Paris.

20. He BY, Soady KA, Mellor BG, Morris A, Reed PAS (2013) Effects of shot peening on short crack growth rate and resulting low cycle fatigue behaviour in low pressure turbine blade material. Mater. Sci. Tech-lond. 29: 788-796.

21. Chaboche JL (1986) Time-independent constitutive theories for cyclic plasticity. Int. J. Plasticity. 2: 149-188.

22. Zhuang WZ, Halford GR (2001) Investigation of residual stress relaxation under cyclic load. Int. J. Fatigue. 23.

23. Soady KA (2013) Reducing conservatism in life assessment approaches: Industrial steam turbine blade to disc interfaces and the shot peening process. University of Southampton.

24. Korsunsky AM, Regino GM, Nowell D (2007) Variational eigenstrain analysis of residual stresses in a welded plate. Int. J. Solids. Struct. 44: 4574-4591.

25. Vasu A, Hu Y, Grandhi RV (2013) Differences in plasticity due to curvature in laser peened components. Surf. Coat. Tech. 235: 648-656.

26. Coratella S, Burak TM, Fitzpatrick ME (2014) Application of the Eigenstrain Theory to Predict Residual Stress around Curved Edges after Laser Shock Peening. Mater. Sci. Forum. 768: 185-192.

27. Kim S-B, Evans A, Shackleton J, Bruno G, Preuss M, Withers PJ (2005) Stress Relaxation of Shot Peened Udimet 720Li under Solely Elevated-Temperature Exposure and under Isothermal Fatigue. Metallurgical and Materials Transactions A. 36: 3041-3053.

28. You C, Achintha M, Soady KA, Reed PAS (Submitted) Low cycle fatigue life prediction in shotpeened components of different geometries - Part II: Life prediction. Fatigue. Fract. Eng. M. 
Tables

Table 1: Material parameters representative of the monotonic mechanical properties of FV448.

\begin{tabular}{|l|l|l|l|l|l|l|l|l|}
\hline$E / \mathrm{GPa}$ & $v$ & $\left.\sigma\right|_{0} / \mathrm{MPa}$ & \multicolumn{5}{|l|}{ Isotropic component } & \multicolumn{4}{|l|}{ Kinematic component } \\
\cline { 4 - 9 } & & & $Q_{\infty} / \mathrm{MPa}$ & $\mathrm{b}$ & $C_{1} / \mathrm{MPa}$ & $\gamma_{1}$ & $C_{2} / \mathrm{MPa}$ & $\gamma_{2}$ \\
\hline 201.3 & 0.3 & 697 & 171 & 35 & 203621 & 1139 & 349 & 0 \\
\hline
\end{tabular}

Table 2: Definition of the eigenstrain and the initial true plastic strain profiles used for the sensitivity analysis.

\begin{tabular}{|l|l|l|l|}
\hline Label & $a$ & $b$ & $c$ \\
\hline Eigenstrain profile & Baseline $+10 \%$ & Baseline profile & Baseline $-10 \%$ \\
\hline True plastic strain profile & Baseline $+17 \%$ & Baseline profile & Baseline $-17 \%$ \\
\hline
\end{tabular}

Table 3: Matrix of the sensitivity analysis.

\begin{tabular}{|l|l|l|l|l|}
\hline \multicolumn{2}{|c|}{} & \multicolumn{3}{|c|}{ True plastic strain profile } \\
\cline { 3 - 5 } \multicolumn{2}{c|}{} & $a$ & $b$ & $c$ \\
\hline \multirow{2}{*}{$\begin{array}{l}\text { Eigenstrain } \\
\text { profile }\end{array}$} & $a$ & $/$ & $a b$ & $/$ \\
\cline { 2 - 5 } & $b$ & $b a$ & $b b$ & $b c$ \\
\cline { 2 - 5 } & $c$ & $/$ & $c b$ & $/$ \\
\hline
\end{tabular}


Figures

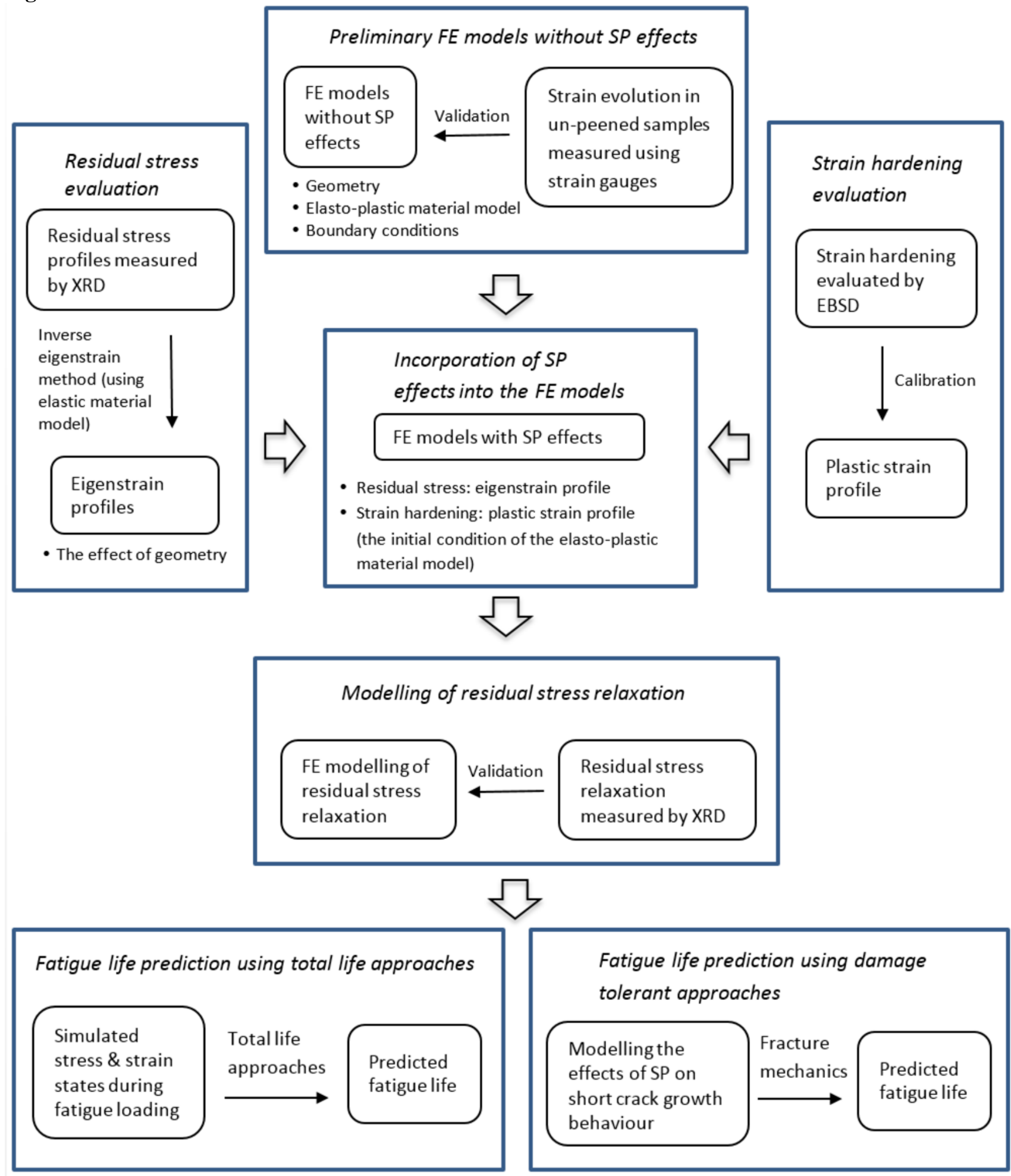

Fig. 1: Flowchart of the modelling work. 

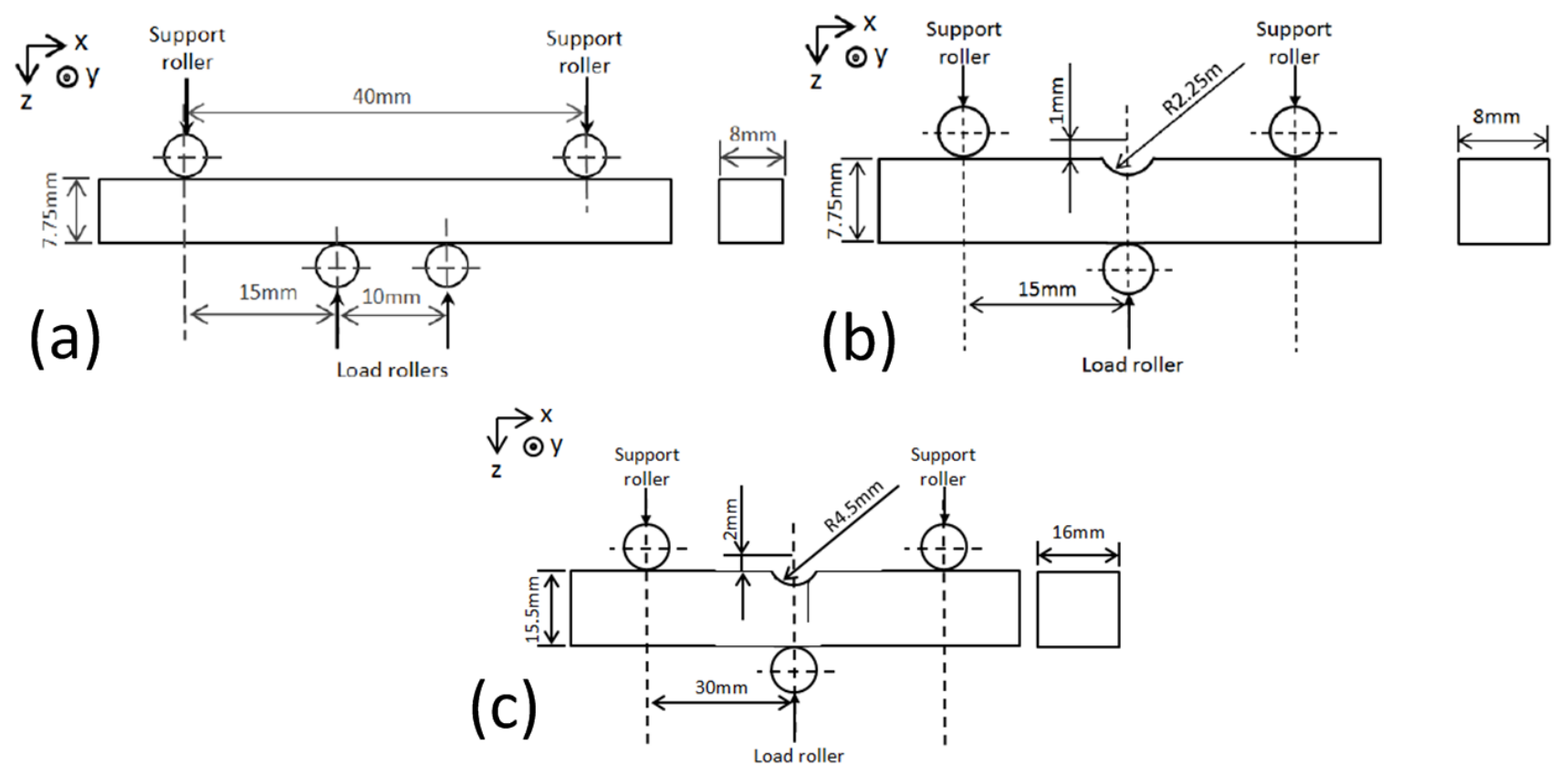

Fig. 2: Dimensions of (a) the plain sample, (b) and (c) the U-notched sample in two sizes.
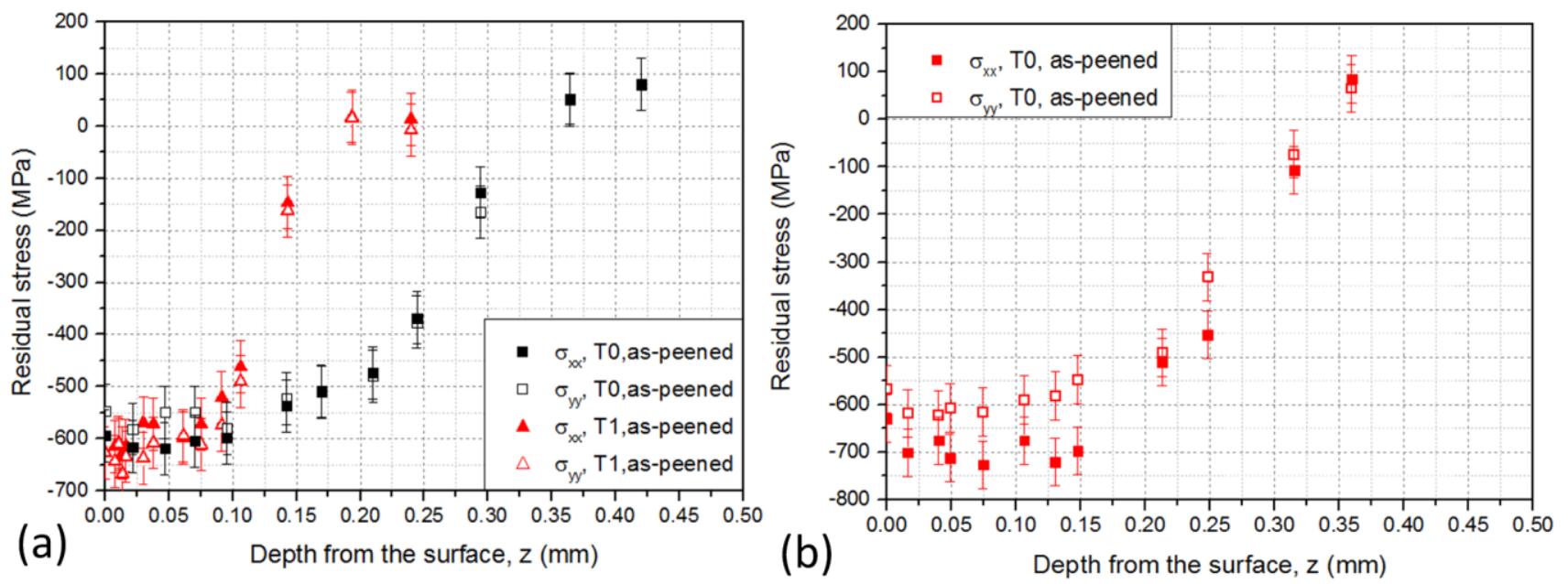

Fig. 3: Residual stress distributions measured by XRD in the shot-peened (a) plain and (b) notched samples. After Soady et al. ${ }^{18}$.
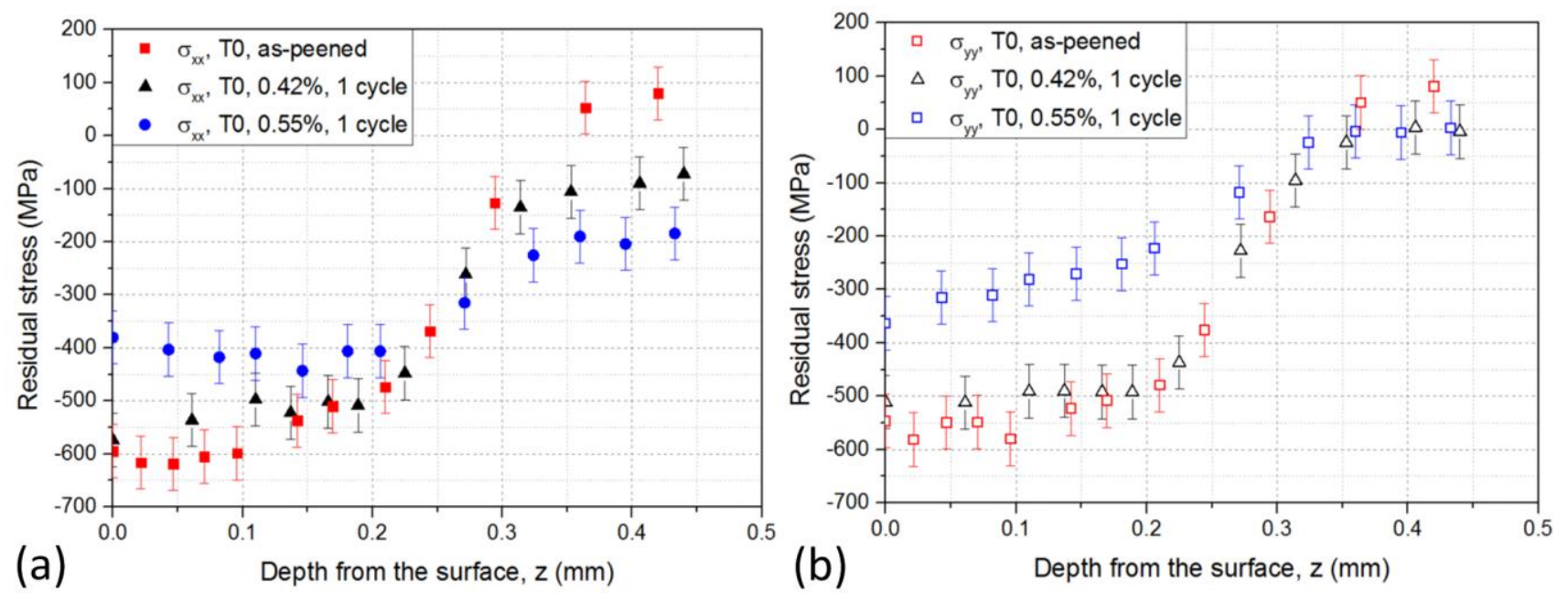
Fig. 4: Residual stress relaxation after 1 cycle in the T0 plain sample $\Delta \varepsilon_{x x} .0 .42 \%$ and $0.55 \%$ ): (a) $\sigma_{x x}$ and (b) $\sigma_{y y}$.
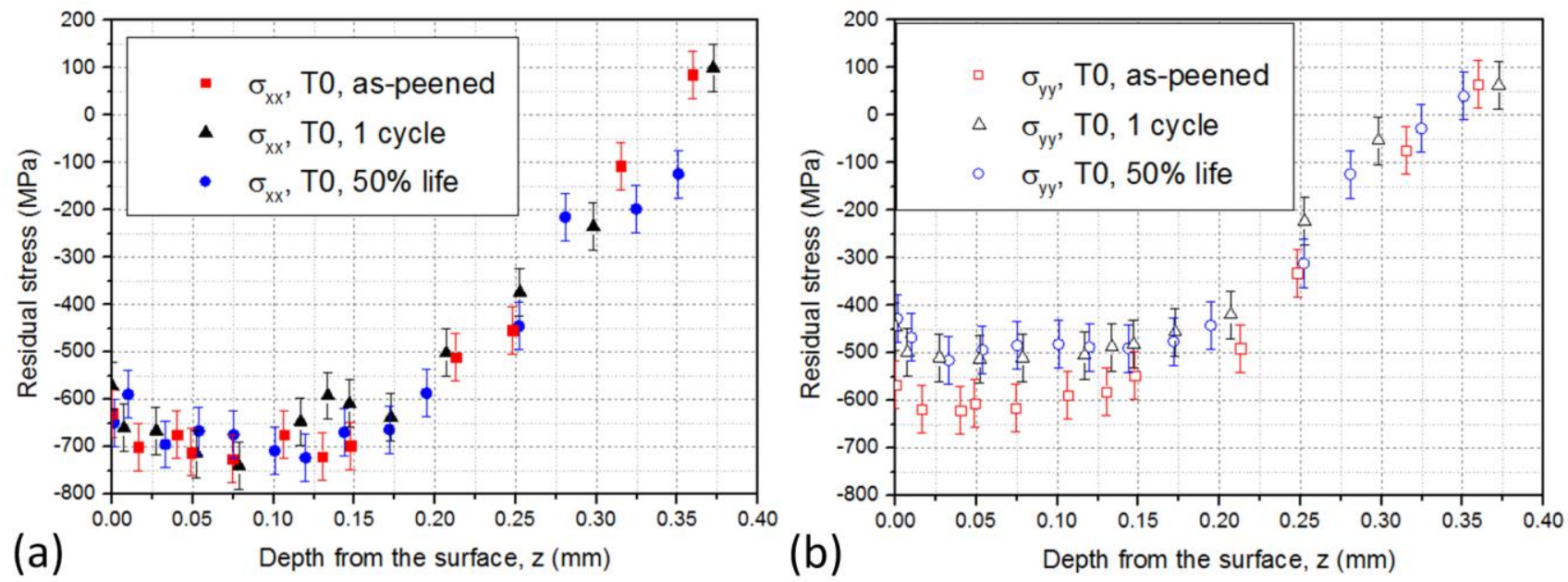

Fig. 5: Residual stress relaxation at different total life fractions in the T0 notched sample $\left(\Delta \varepsilon_{x x}=0.69 \%\right.$ ): (a) (a) $\sigma_{x x}$ and (b) $\sigma_{y y}$. After Soady et al. ${ }^{18}$.
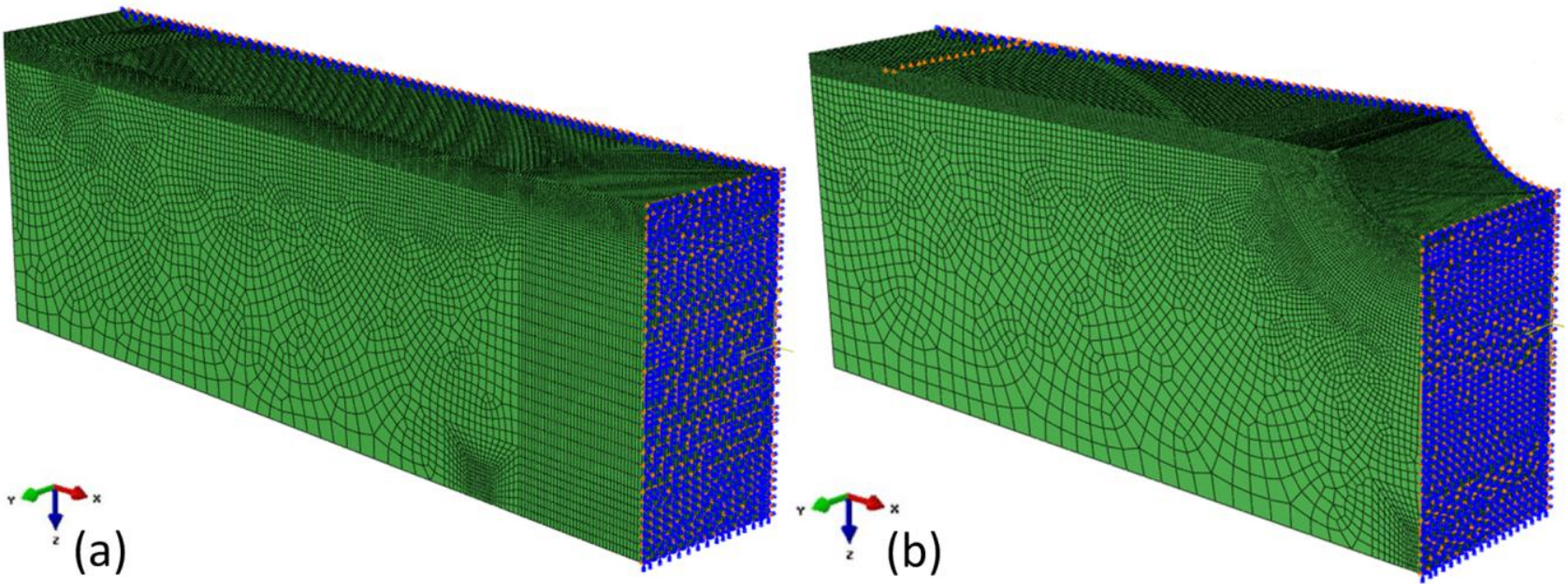

Fig. 6: FE models for the (a) plain and (b) U-notched samples.
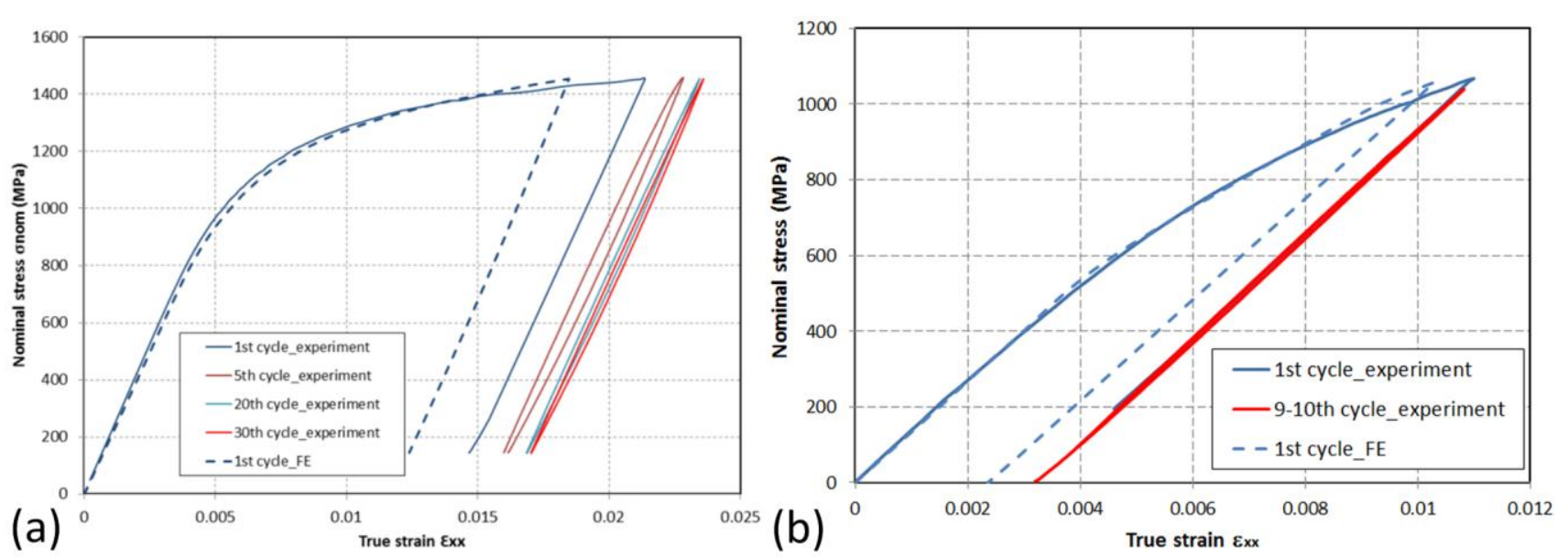

Fig. 7: Comparison between the strain evolution obtained by experiments and modelling in the un-peened (a) plain and (b) notched samples. 

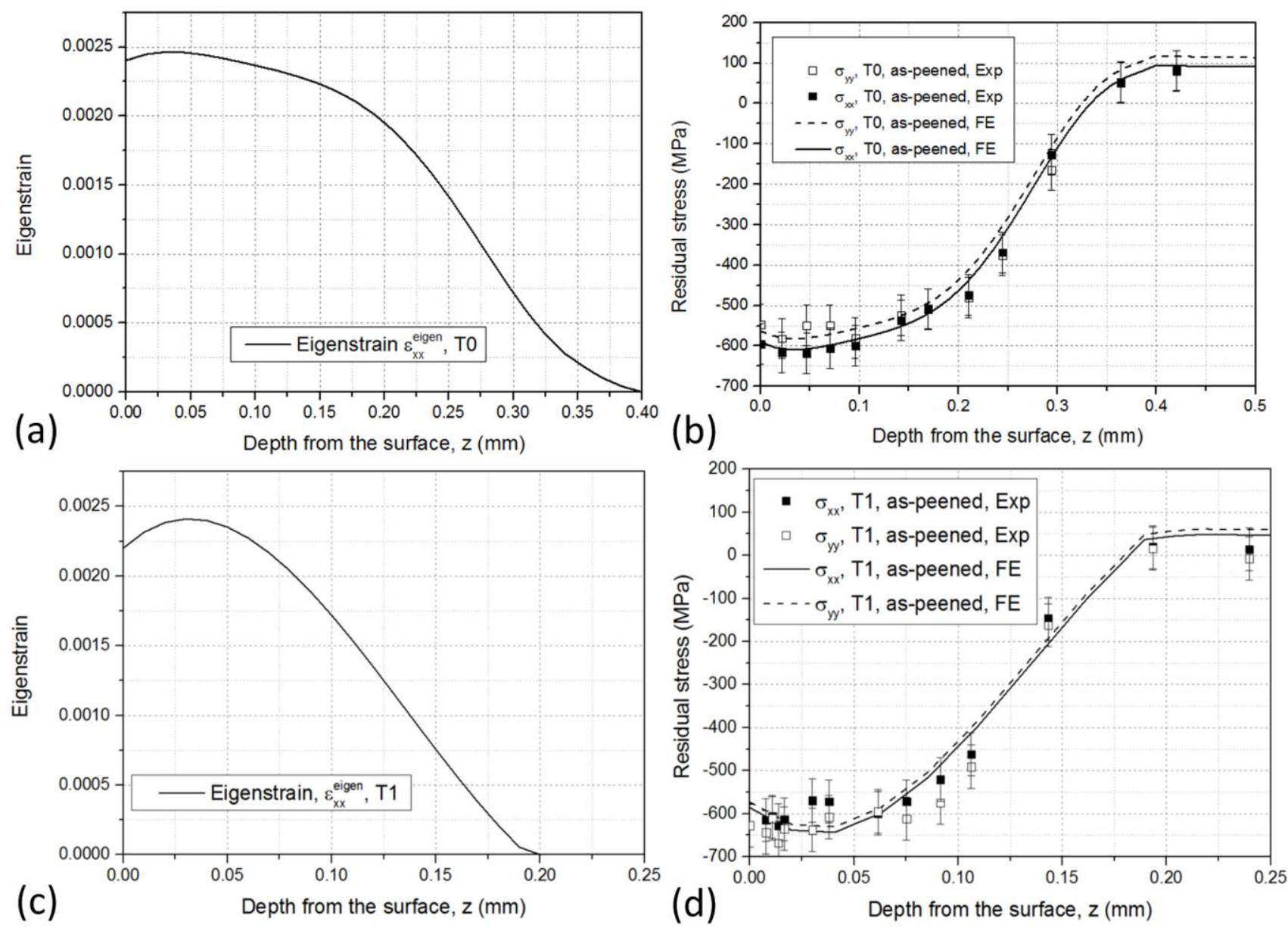

Fig. 8: Predicted eigenstrain profiles, $\varepsilon_{x x}^{e i g e n}(z)$, for the (a) T0 and (c) T1 processes and the comparison between the reconstructed and measured residual stress data in the (b) T0 and (d) T1 plain samples. 

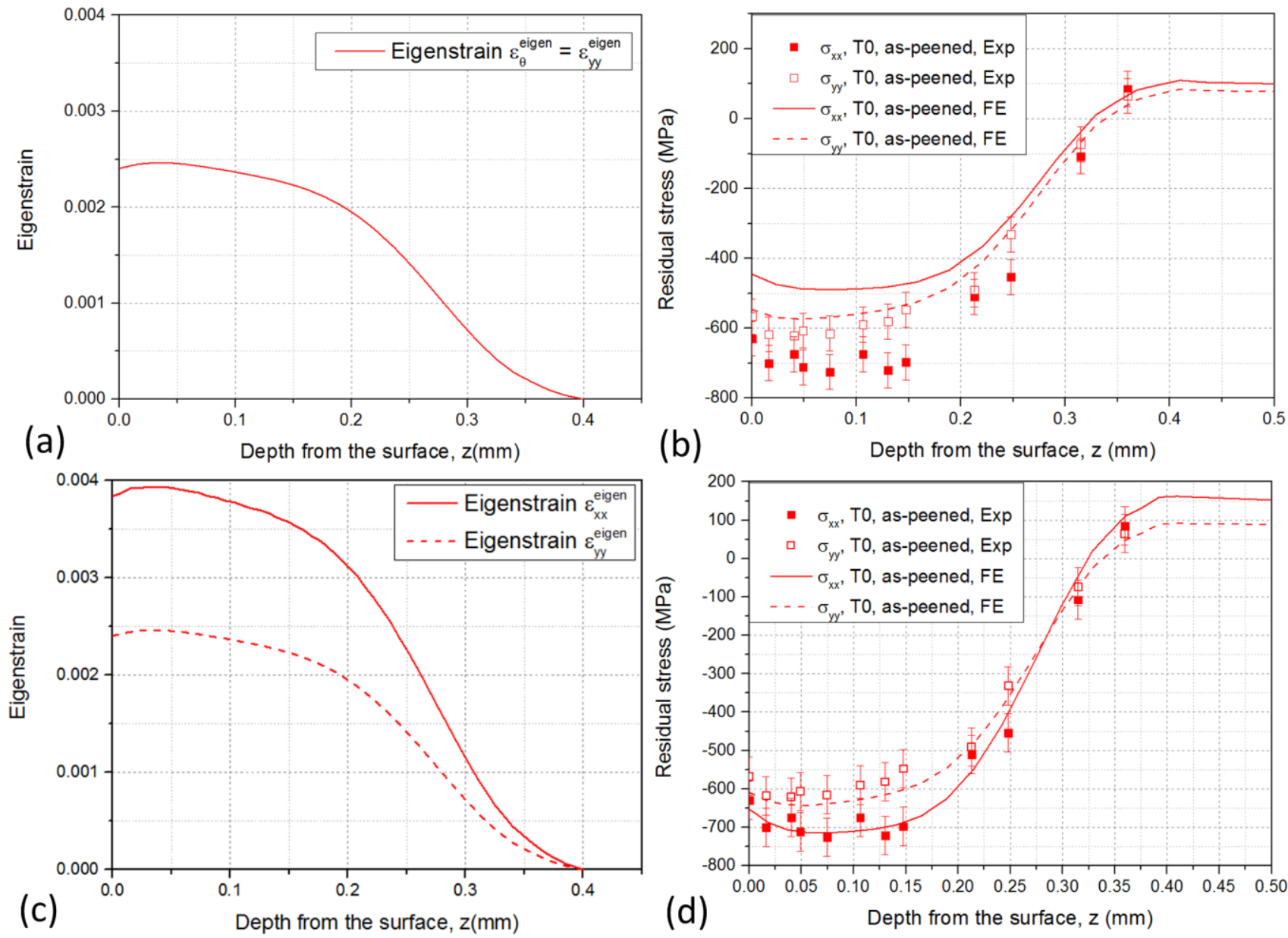

Fig. 9: A comparison between two eigenstrain assumptions in the T0 notched sample: (a) the equi-biaxial eigenstrain profiles and (b) the reconstructed residual stresses; (c) the predicted biaxial eigenstrain profiles and (d) the reconstructed residual stresses. 


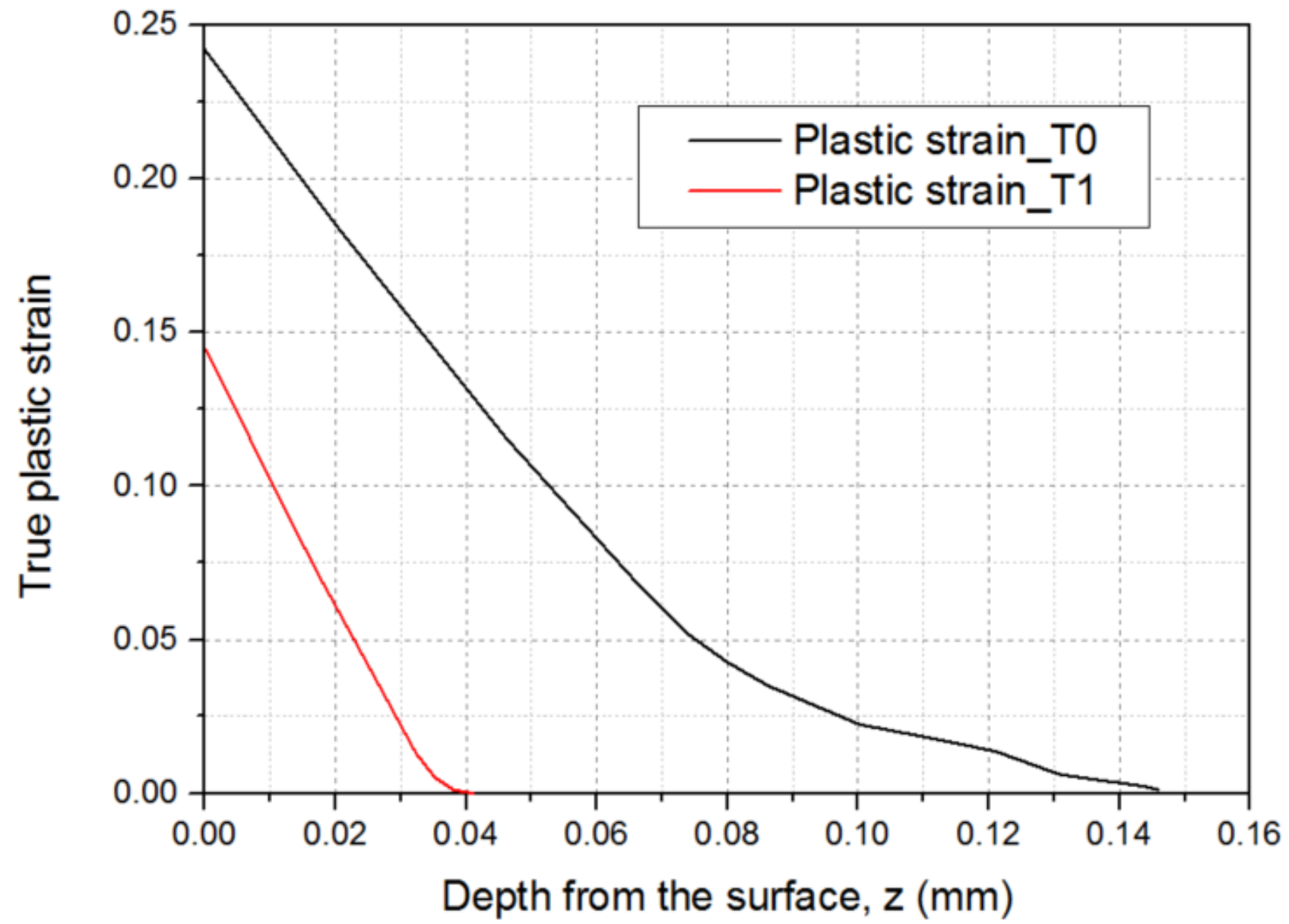

Fig. 10: Predicted true plastic strain distributions caused by the T0 and T1 shot peening. After Soady et al. ${ }^{2}$. 

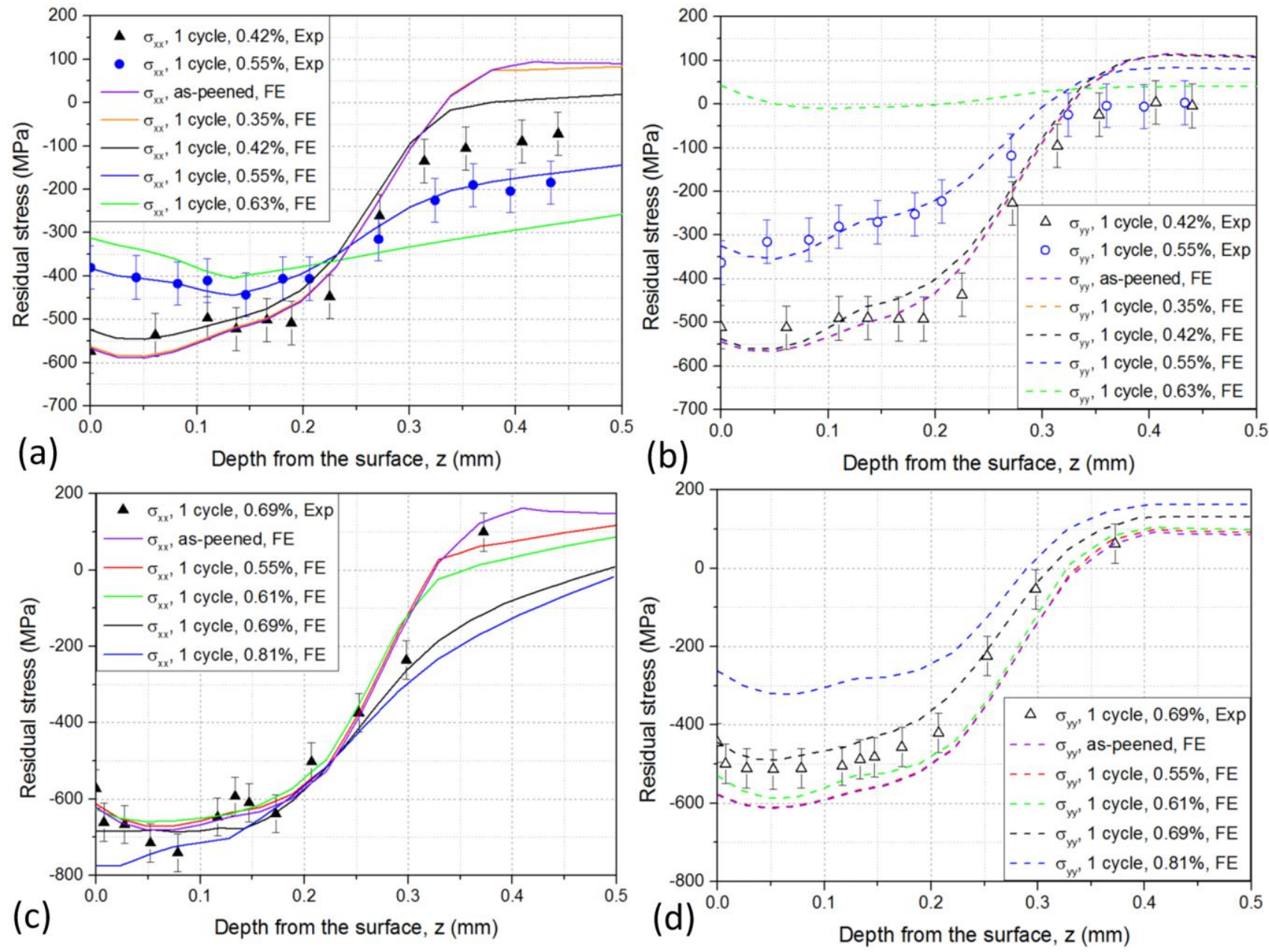

Fig. 11: Simulated relaxation of (a) $\sigma_{x x}$ and (b) $\sigma_{y y}$ in the T0 plain sample, (c) $\sigma_{x x}$ and (d) $\sigma_{y y}$ in the T0 notched sample after 1 cycle at different load levels in terms of $\Delta \varepsilon_{x x}$. 

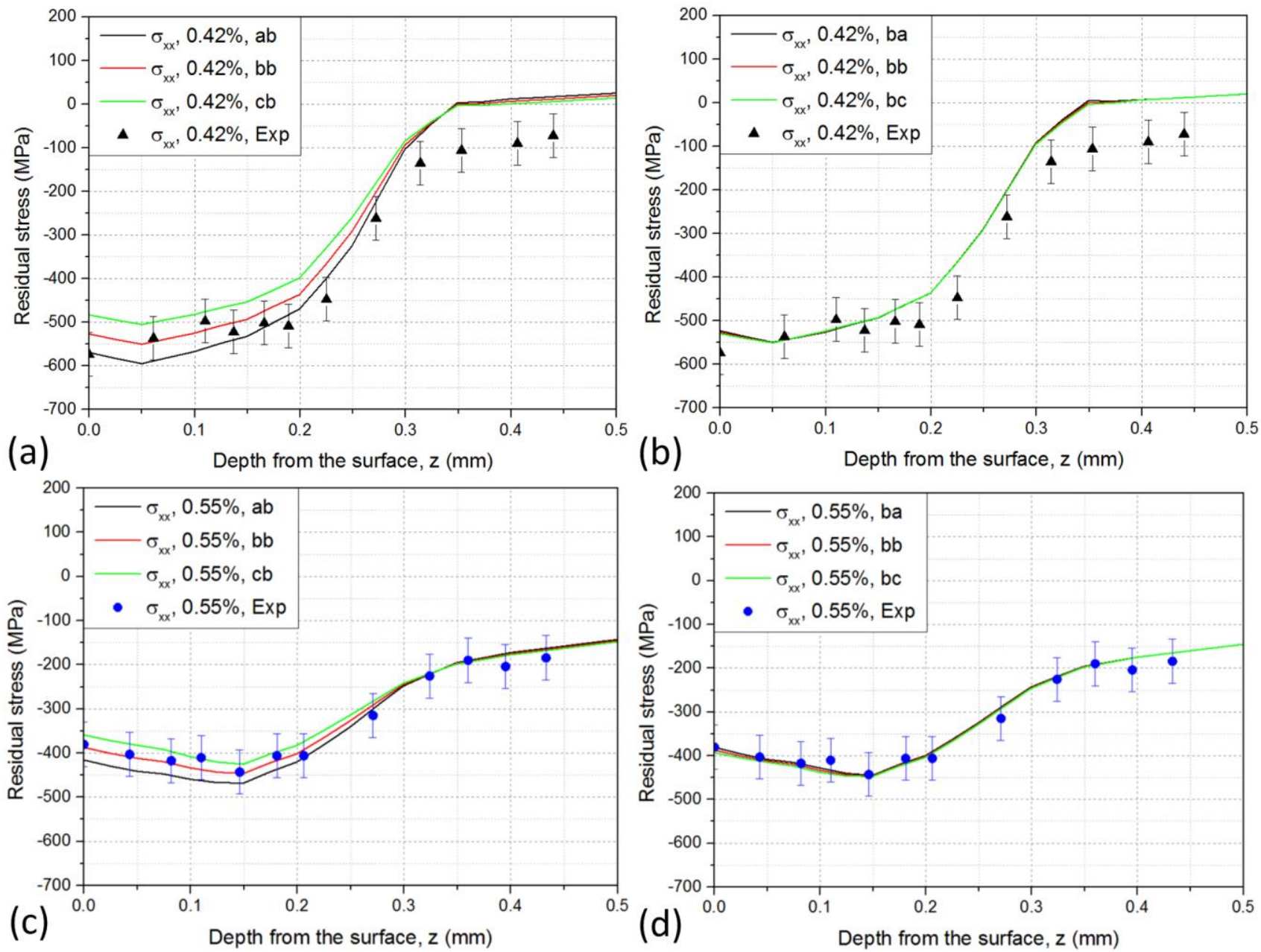

Fig. 12: Sensitivity analysis results for the T0 plain sample; the effects of the initial (a) (c) residual stress and (b) (d) strain hardening profiles when $\Delta \varepsilon_{x x} .=0.42 \%$ and $0.55 \%$. 